\title{
Sobre las antinomias de enseñar filosofía
}

Walter Omar Kohan

Universidad del Estado de Río de Janeiro, Brasil

\begin{abstract}
Resumen: Este texto se estudia una serie de antinomias, propias de la enseñanza de la filosofía. Se detiene en dos propuestas de J. Derrida y F. Wolff para proponer un modo específico de pensar ese campo en torno del nombre de Sócrates. Se trata así, de pensar un enseñar y aprender filosofía políticamente interesantes o, de un modo más amplio, para una educación filosófica, alrededor de las siguientes seis exigencias: a) la autonomía necesaria e imposible; b) la transmisión de lo intransmisible; c) el saber la ignorancia; d) el método y su ausencia; e) dentro y fuera de los muros; f) transformar y descolonizar.
\end{abstract}

Palabras clave: Sócrates, J. Derrida, F. Wolff, enseñanza de la filosofía

\begin{abstract}
This text studies a series of antinomies, belonging to the teaching of philosophy. It stops in two texts of J. Derrida and F. Wolff to propose a specific way to think that field, around the name of Socrates. The aim is to think a politically interesting teaching and learning of philosophy or, in a broader sense, a philosophical education, around the following six demands: a) the necessary and impossible autonomy; b) to transmit what is impossible to be transmitted; c) to know the ignorance; d) the method and its absence; e) inside and outside the walls; f) to transform and to decolonize.
\end{abstract}

Key words: Socrates, J. Derrida, F. Wolff, Teaching philosophy 
$\mathrm{E}$ n 1980 J. Derrida publica un libro escrito a partir de una tarjeta postal que ha encontrado en la Biblioteca Bodleiana de Oxford. La tarjeta muestra a Sócrates sentado, agachado, escribiendo y a Platón detrás, más pequeño, con el dedo índice hacia arriba. La figura hace delirar a Derrida, le parece encontrar en ella lo que siempre buscó: "el camarada Sócrates fue el primer secretario del partido platonista". En la tarjeta, Platón, magistral, dictatorial, muestra el camino, da una orden a su escriba (1980, p. 13-4). Por su parte, Sócrates le da la espalda a Platón para escribir. La tarjeta consuma el sueño de Platón: hacerlo escribir a Sócrates, ser el padre de su padre. Derrida se pregunta: ¿qué escribe Sócrates? ¿A quién? "Son aún el enigma absoluto, esos dos" (ibid., p. 56).

\section{Las exigencias de la institución filosófica, según J. Derrida}

J. Derrida se ha ocupado intensamente de la enseñanza de la filosofía, sobre todo en los años 70 y 80 . Sus textos están reunidos en un extenso volumen $D$ u droit a la philosophie (1990), que incluye trabajos teóricos, documentos del GREPH (Groupe de Recherches sur 1’Enseignement Philosophique) y una serie de intervenciones públicas. A continuación nos referirnos a uno de esos textos, que Derrida escribió bajo la forma de una carta a los participantes de un evento en $1984^{1}$.

En esa carta, sin referirse explícitamente a Sócrates o Platón, J. Derrida ha planteado una serie de demandas contradictorias de la institución filosófica. Derrida fija el número de esas exigencias en siete. A continuación, las describimos sintéticamente.

a. Los condicionamientos externos

Por un lado, Derrida sugiere que es necesario responder a cualquier ingerencia externa sobre la filosofía. Esa pretensión puede ser dada por un propósito establecido en relación con lo útil, lo conveniente, lo productivo, lo eficaz, lo rentable, pero también por la racionalidad técnico-científica e incluso la educación ética, cívica o política. Por otro lado, parece igualmente inconveniente que la filosofía abandone su función crítica, de juez, jerarquizante, que la razón filosófica no se constituya en instancia final del juzgamiento, en crítica de las razones y finalidades últimas. En otras palabras, es imposible para la filosofía no enfrentarse a la vez a dos tipos de racionalidad, interna y externa. ¿Cómo conciliar esos dos regímenes de finalidad, esas dos instancias jerarquizantes, del interior y del exterior?

b. El cierre y la apertura, la unidad y la multiplicidad

Derrida afirma que es necesario enfrentar el confinamiento de la filosofía sobre ella misma, sea en la forma de un curso, un centro, una lógica, un contenido o cualquier otra

1 Se trata del Colloque Rencontres École et Philosophie, que tuvo lugar en la Universidad de Paris X, Nanterre, los días 20 y 21 de octubre de 1984. Este texto, titulado "Les antinomies de la discipline philosophique", fue primeramente publicado como prefacio al libro de Jacques Derrida et al. La grève des philosophes. École et philosophie. Paris: Osiris, 1986, y después reproducido en el ya citado libro de J. Derrida Du droit à la philosopbie, 1990, p. 511-524. 
forma fija. En todos los casos, es necesario resistir esa negativa de encontrar otros objetos, de estar presente en otros cursos, de abrirse a nuevos contenidos y a espacios desconocidos. Sin embargo, al mismo tiempo es también legítimo aspirar a cierta unidad o especificidad de la disciplina. En otros términos, es necesario abrir la filosofía a las otras disciplinas, pero sin que esa apertura descaracterice la propia filosofía. Derrida se pregunta en qué medida es posible conciliar "esa identidad localizable con esa ubicuidad desbordante."

\section{c. Enseñar lo inenseñable}

Sostiene Derrida que a través de toda su historia, la filosofía ha estado reivindicando su dimensión educacional. Sin embargo, algo de esencial en la filosofía resta sin poder ser enseñado, inenseñable. Desde su origen la filosofía parece envuelta en esa paradoja: no resiste a la tentación de ser enseñada y, sin embargo, no puede, en su gesto principal, ser enseñada.

\section{d. Institucionalizar la filosofía}

La filosofía, afirma Derrida, es una "disciplina imposible y necesaria; inútil e indispensable." Los profesores de filosofía exigen, naturalmente, la creación de nuevas instituciones filosóficas. A la vez, saben que la filosofía sobrepasa sus instituciones inexorablemente; que ella, a decir verdad, no puede ser institucionalizada. La filosofía no conocería otra "institución" que la verdad, la idea, sus preguntas, y ellas no pueden tener la forma de una institución.

e. Dependencia o independencia

Para subsistir el profesor de filosofía tiene que ocupar una posición de exterioridad frente a la propia filosofía. Es necesario que el filósofo se convierta en un profesor y, en cuanto tal, tenga alumnos, ocupe cargos académicos, haga concursos, en otras palabras, se someta a una lógica externa a la comunidad filosófica. Aun con la amplitud de los espacios ocupados por los filósofos en nuestros días -prestadores de servicios, animadores de cafés filosóficos, consultores, etc.- la situación no ha variado sino que, en cierto modo, se ha agravado en la medida en que los condicionamientos institucionales se han relajado sólo en apariencia. Derrida sostiene que toda esa exterioridad no debe imposibilitar la autonomía que exige el trabajo filosófico para que pueda ser llamado tal.

\section{f. La temporalidad de la enseñanza}

Hay un tiempo exigido por la experiencia filosófica del pensar. El trabajo conceptual tiene sus ritmos, su duración, y cierta avidez por prolongarse siempre un poco más. Frente a esta temporalidad filosófica, la disciplina filosofía se encuentra con otros tiempos: el del cronograma de la escuela, de los semestres, de las horas de la clase, de los programas, de las fechas de los exámenes, de los momentos para pasar de un nivel a otro de escolaridad. ¿Son compatibles estas dos temporalidades? ¿Cómo la filosofía puede tornar compatible esa doble exigencia temporal? 
g. Iniciación por un maestro vs. autodidactismo

Las condiciones de la filosofía son dadas por un maestro, alguien que inicia a los que se forman en filosofía. La cadena se prolonga: el maestro es a su vez iniciado por otro maestro y el discípulo, en su momento, iniciará a otros discípulos. Así, se constituye una "heterodidáctica" en la que el maestro, intercesor, guardián, garante representa el pensar. Con todo, reconocer esta iniciación necesaria no puede suponer negar la autonomía no menos indispensable de la actividad filosófica, su autodidactismo.

Hasta aquí, las demandas contradictorias presentadas por Derrida quien explicita que el número de siete es arbitrario. De sus exigencias, él extrae tres consecuencias: a) constituyen una matriz central que incluye la totalidad de los tipos de enunciados producibles en torno al tema "escuela y filosofía"; b) una comunidad filosófica deseable es aquella que no niega esas demandas, sino que piensa lo que puede surgir a partir de ellas; c) ¿esas exigencias son históricas o a-históricas? Si son históricas, ¿cuál es su ley, su "articulación progresiva”?

La primera consecuencia parece exageradamente pretenciosa; pero, acotando sus pretensiones, ¿quién puede negar que estas exigencias configuran gran parte de las cuestiones actualmente implicadas en la relación entre escuela y filosofía? La segunda retrata un elemento esencial de una actitud filosófica: ¿qué podemos esperar, aquí y ahora, de esa práctica paradójica, imposible y necesaria que es la enseñanza de la filosofía? Una comunidad filosófica que merezca ese nombre hace de sus condiciones paradójicas una oportunidad para pensarse a sí misma.

\section{Las exigencias socráticas, según F. Wolff}

Vamos a reformular esas exigencias a partir de algunos elementos que Sócrates y algunos de sus lectores nos proveen. Antes vamos a acudir a otro autor que propone, más específicamente, paradojas propiamente socráticas que, en cierto modo, se entrecruzan con las de Derrida. El énfasis aquí está puesto en quien aprende filosofía. Después de describirlas, tomaremos algunos elementos de unos y otros para plantear nuestro propio esquema.

En efecto, Francis Wolff ${ }^{2}$ destaca tres aspectos de la paradoja de Sócrates desde la perspectiva del discípulo: ¿cómo es posible "lo socrático"? ¿Cómo es posible que la inmensa parte de las escuelas filosóficas de la antigüedad reconozcan raíces comunes en Sócrates? Según Wolff, todo discípulo supone un maestro, una disciplina y condiscípulos y en los tres elementos ser discípulo de Sócrates es problemático. Así, Sócrates deja para todos sus seguidores una triple tensión que se podría formular así: ¿cómo ser discípulo de quien: a) dice que no es maestro de nadie; b) no reconoce estar transmitiendo ningún saber; c) no genera escuela (no hay socráticos trabajando unos con otros sino unos contra otros)? ${ }^{3}$ De modo que la paradoja de Sócrates es que hay infinidad de discípulos sin

2 F. Wolff, 2000. Véase, sobre todo, el capítulo siete, "Être disciple de Socrate”, p. 209-251. 
maestro, sin disciplina y sin condiscípulos. ¿Cómo puede entenderse este escándalo abierto por Sócrates?

F. Wolff da vuelta las cosas. No sólo no se trata de un escándalo sino que esta paradoja expresa la "función más general de todo discípulo" (2000, p. 213) y de un modo más específico la configuración socrática del discípulo. ¿En qué consiste esta solución? Por un lado, cuanto más un maestro se niega a ocupar el lugar de maestro, más necesidad tiene el discípulo de decirse discípulo de ese maestro. Sócrates es el caso límite en el que el discípulo es puro discípulo, sin maestro. Por otro lado, cuanto menos el maestro ha fijado una doctrina, mayor es la necesidad del discípulo de fijar la doctrina del maestro. Sócrates es el ejemplo límite en que toda la doctrina la fija el discípulo. Finalmente, cuanto mayor es el número de los que se dicen discípulos del mismo maestro, mayor es la necesidad de afirmarse como discípulo contra otros condiscípulos. Sócrates es el caso extremo en que todos los filósofos que lo suceden se dicen condiscípulos del mismo maestro.

Esta posición socrática lleva a Wolff a cuestionar si de hecho se trata en el caso de Sócrates de relaciones de maestro y discípulo. A través de un examen de la terminología usada para referirse a Sócrates desde sus seguidores hasta los doxógrafos, Wolff saca dos conclusiones: a) los términos 'maestro' (äéä óêáëïò) y ‘discípulo' (ìáèçô ò) para referirse a Sócrates y sus seguidores sólo aparecen en una tradición muy posterior y tardía; antes, se habla de Sócrates como 'amigo' (ö Oë ï í), ‘camarada' (åôáã̃̃ïò) y de sus seguidores como "los que pasan su tiempo con él” (Aé óõiaaéâônOâiíîồ) y "los que están con él” (Aé óõíîíôò); este cambio en la terminología es paralelo a un cambio en la concepción de la filosofía que pasa de ser un modo de vida y un cierto tipo de vida colectiva o comunitaria a una serie ordenable de doctrinas filosóficas; b) la relación entre Sócrates y sus seguidores tiene tres características principales: 1) conlleva la vida en común (y no sólo posiciones intelectuales); 2) exige afecto (filial o amoroso, y no sólo la neutralidad de la transmisión de conocimientos o de un saber hacer); 3) se basa en el diálogo, palabra simétrica (y no sólo la enseñanza unilateral de maestro a discípulo, ibid., p. 221).

Al fin, Wolff se interesa en determinar lo que significa ser discípulo de Sócrates. Se concentra en cuatro figuras (Aristipo, Antístenes, Euclides y Platón) y da una respuesta doble. Ser discípulo de Sócrates es, en primer lugar, participar de un modo de vida en común y de un método dialéctico -élegkoj - que busca instalar en los dialogantes la armonía entre lo que se piensa, lo que se dice y lo que se hace; en segundo lugar, significa hacer lo que no ha hecho Sócrates, elaborar una "filosofía moral", definir el bien, un principio universalizable, que funde un sistema moral coherente (ibid., p. 250-1).

La interpretación de Wolff da un Sócrates demasiado coherente, monolítico, incólume. Creemos que no es tan simple responder lo que significa ser discípulo de Sócrates. El enigma es más radical. Si de verdad escuchamos la negación de Sócrates a ocupar el lugar de maestro y la diversidad de relaciones que establece con sus diversos interlocutores, "ser discípulo (o amigo, camarada) de Sócrates" da lugar, antes que a una respuesta única, a una serie de exigencias antinómicas que profundizan el enigma. Ser discípulo de Sócrates es: 1)

3 Op. cit., p. 210-211. 
participar de una vida en común, pero también de una vida individual marcada por cierto tipo de cuidado, de atención y de examen de sí mismo y de los otros; esto significa también participar de un cierto modo de terminar la vida, de enfrentar la muerte, de morir; 2) envolverse con el otro dialogante en una relación de afecto y de desafecto, de búsqueda y de abandono, de conquista y desaire; 3) valorar un juego dialéctico que es simétrico pero también asimétrico, con algunos puntos fijos, como a) el valor que Sócrates atribuye a su relación con el saber; b) el carácter de misión que él considera llevar a cabo al conversar con todos los otros y c) sus elecciones de vida, no participar de la política instituida, no cobrar por enseñar, etc.

\section{Algunas exigencias socráticas}

Sabemos que Sócrates no escribió nada, con excepción de un himno a Apolo y una producción propia sobre narraciones de Esopo, por él mismo mencionados (Platón, Fedón 60d), y de los cuales nada conservamos. ¿Dónde, entonces, encontrar su pensamiento? Los testimonios que conservamos son de amigos o enemigos, todos escritores con estilo, ideas y sentidos propios, lo que vuelve la cuestión todavía más delicada. Hay cuatro fuentes principales entre las conservadas de la literatura clásica: un comediante (Aristófanes), un historiador (Jenofonte), y dos filósofos (Platón y Aristóteles). Hay también referencias diseminadas en biógrafos, historiadores, y otros escritores bastante posteriores. Infelizmente, no conservamos ninguno de los treinta y tres diálogos socráticos escritos por su contemporáneo y zapatero Simón de Atenas. Según Diógenes Laercio, Simón habría sido el primero en introducir el método socrático en las conversaciones (Vidas, II 121).

Algo es seguro: habiéndolo o no deseado, Sócrates hizo escuela. Incluso Aristófanes inventó, en vida de Sócrates, un verbo, "socratear", para referirse a sus discípulos, aquellos que "siguen las costumbres de Esparta, se dejan crecer los cabellos, pasan hambre y se niegan a lavarse" (Aves 1280-4). Resulta interesante que Aristófanes haya sentido la necesidad de inventar un verbo para retratar la acción específica de los que estaban en contacto con Sócrates. Entre esos discípulos están, por ejemplo, Querefonte y Apolodoro (Clay, 1994, p. 25). Sin embargo, los seguidores inmediatos de Sócrates y los que reivindicaron ser continuadores de la tradición socrática en el período helenístico eran de todo menos un grupo pequeño y homogéneo. Un siglo después de su muerte, las principales figuras de las escuelas filosóficas helenísticas -el estoico Zenón y el académico-escéptico Arquesilaoreivindicaban igualmente su nombre (P. Waerdt, 1994, p. 7 ss.). La más completa edición contemporánea de los fragmentos de Sócrates (G. Giannantoni, 1990) ofrece una lista de aproximadamente setenta socráticos, entre los seguidores inmediatos y los más distantes. De hecho, en el Fedón de Platón aparecen listados casi veinte (59b-c). En esta rica tradición se encuentran posturas filosóficas diversas e incluso antagónicas sobre problemas comunes; hay en ella también formas enfrentadas de concebir, practicar y escribir la filosofía.

Aristóteles (Poética II 1447b) menciona un género específico, los escritos o diálogos socráticos -sokratikoi lógoi-, que imitaban las conversaciones de Sócrates. Además de 
Platón y Jenofonte, los más importantes escritores de diálogos socráticos habrían sido Antístenes, Aristipo, Critón, Simón, Euclides de Megara, Fedón y Esquines. Conservamos algunos fragmentos de Antístenes y de Esquines. Cuando Platón escribió sus diálogos, el género ya era reconocido en Atenas (Clay, 1994, p. 27-30). Jenofonte no es mencionado nunca en los diálogos de Platón y este aparece sólo una vez en los Memorabilia (II.6.1). Diógenes Laercio hace referencia a una supuesta rivalidad entre ambos (Vidas, III, 34). Jenofonte menciona repetidas veces a Antístenes en el Banquete y a Aristipo en Memorabilia. Platón menciona a Antístenes y a Aristipo sólo para confirmar sus respectivas presencia y ausencia en el momento de la muerte de Sócrates (Fedón 59c) y a Esquines para confirmar, además, su presencia en el juicio (Apología de Sócrates, 33e). Platón y Jenofonte son los únicos autores de sokratikoi lógoi que conservamos enteros y ofrecen un testimonio muy desigual.

Platón compartió los últimos años de Sócrates (tenía cerca de treinta años cuando murió), estuvo personalmente en los acontecimientos que desencadenaron en su condena y su muerte. Hizo de Sócrates personaje de casi todos sus Diálogos. Fue probablemente el único entre los escritores de diálogos socráticos que los dotó de un ambiente histórico. La Apología de Sócrates, Critón y Fedón narran los acontecimientos en torno da muerte de Sócrates: la Apología, su juicio y defensa; el Critón. un intento de convencer a Sócrates de escapar de la prisión y el Fedón los momentos inmediatamente anteriores a su muerte en prisión. Los otros diálogos tienen como escenarios espacios de Atenas -casas, gimnasios, calles, etc.- y muchos empiezan describiendo el ambiente y la circunstancia en que la conversación tendrá lugar. De todos modos, no hay cómo saber si se trata de relatos más o menos realistas o simplemente ficciones. Ya en la propia Antigüedad, Platón fue criticado por el anacronismo de sus escenarios (Clay, 1994, p. 44, n. 46) e inclusive el autor de la peudo-platónica Carta II dice que, en los diálogos, Sócrates está "embellecido y rejuvenecido" (314c).

El testimonio de Jenofonte es más indirecto. Aunque haya conocido personalmente a Sócrates, no estaba en Atenas al menos desde un año antes de su muerte: era uno de los mercenarios griegos del ejército de Ciro en el Asia Menor (Clay, 1994, 31-2) y no volvió a Atenas antes de 394 a.C., o sea, unos cinco años después de la muerte de Sócrates (T. Brickhouse, N. Smith, 1989, p. 1). Sus dos principales escritos sobre Sócrates, Apología y Memorabilia (que contiene una segunda apología en I, 1-2), se derivarían, en buena medida, de otros testimonios (Clay. 1994, p. 42, n. 43) y el propio Jenofonte se declara en deuda con una apología escrita por Hermógenes (Jenofonte, Apología de Sócrates II, 27 y Memorabilia V, 8, 4-11). El principal interés de la segunda apología sería responder a acusaciones formuladas, en un panfleto escrito por Polícrates, con posterioridad a las primeras apologías (la de Hermógenes, la de Platón, la suya y tal vez otras) probablemente entre 387 e 385 a. C., o sea casi quince años después de la muerte de Sócrates (Eggers Lan, 1986, p. 43 ss.).

Además de Platón y Jenofonte, conservamos el ya mencionado Aristófanes. Este comediante vivió y escribió en tiempos de Sócrates. Hizo de Sócrates personaje principal de una de sus comedias, Las Nubes, la más conocida para nosotros aunque no haya sido 
la más reconocida en su tiempo. En efecto, Las Nubes fue escrita originariamente para la Gran Dionisíaca de 423 a. C. (cuando Sócrates tenía algo más de 45 anos), en la cual ocupó el tercero y último lugar, atrás de obras de Cratino y Amipsia. En la ocasión, Aristófanes tenía alrededor de 25 años. La versión que conservamos de Las Nubes fue parcialmente re-hecha entre los años 419 y 417. Aristófanes también alude directamente a Sócrates en Aves, 1280-4, 1553-5 y 1564; y en Ranas, 1491-1499.

Muchos atenienses se rieron de Sócrates gracias a Aristófanes. El propio Sócrates lo menciona en la Apología de Platón como fuente de los más antiguos acusadores (19c). Si esa composición contribuyó a retratar una imagen "falsa" de su persona, de acuerdo con la percepción de Sócrates, justamente por ello no se trata de una referencia despreciable tratándose de un conciudadano de Atenas. Más todavía, la cuestionable participación política que de hecho tuvieron algunos de los más próximos seguidores de Sócrates -como Cármides y Alcibíades- muestra que al menos una de las acusaciones que hacen Las Nubes, esto es, que los discípulos de Sócrates aprendían a imponer los argumentos injustos sobre los justos, no era de forma alguna improcedente.

Otro testimonio sustantivo es el de Aristóteles. Sin embargo, es mucho más distante e indirecto ya que, cuando Aristóteles nació (en 384 a. C.) ya habían pasado quince años de la muerte de Sócrates. Aristóteles sólo conoció a Sócrates por sus discípulos, sobre todo Platón. También sabemos que Aristóteles no era precisamente un historiador de la filosofía sino un filósofo con categorías muy fuertes al "leer" a quienes lo precedieron, de modo que su Sócrates es como no podría ser de otro modo, un Sócrates demasiado aristotélico.

Aunque durante la Antigüedad helenística el testimonio de Platón recibiera más o menos el mismo tratamiento que el de Jenofonte (Long apud Waerdt, 1994, p. 7, n. 18), modernamente, los filósofos e historiadores de la filosofía terminaron por privilegiar el primero. Las razones son diversas y todas dicen respecto de la propia filosofía. Sócrates es una especie de padre para la filosofía y, para hablar del padre, nada mejor que los testimonios de dentro de casa. Pero no es sólo eso: el valor filosófico de los Diálogos frente a los otros testimonios es innegable. Entre los textos conservados, ninguno llegó filosóficamente tan a fondo cuanto Platón. Tal vez por las condiciones materiales de un aristócrata, por una cuestión de talento, de simpatía, de olfato, de amistad, de amor, por todo eso o alguna otra cosa misteriosa atravesando la relación entre alguien que enseña y otro que aprende, el resultado de la inspiración socrática en Platón es impresionante. Quizá por eso, como ninguno de los testimonios ofrece una versión históricamente muy confiable de las ideas de Sócrates, los estudiosos privilegian el registro más interesante. Con todo, en los últimos años surgieron, entre los helenistas contemporáneos, movimientos contrarios para privilegiar algunos otros testimonios que los platónicos (cf., por ejemplo, el trabajo de P. Waerdt (org.), 1994).

Como el texto y la imagen de Sócrates que ofrecen los Diálogos de Platón son complejos, polémicos, contradictorios, los retratos de Sócrates tienen una característica semejante: es elogiado y recuperado desde perspectivas filosóficas, pedagógicas y políticas encontradas y también es, igualmente, impugnado por voces fuertemente discordantes en sus presupuestos teóricos y epistemológicos. 
La paradoja de Sócrates podría entonces formularse también en relación con sus intérpretes y no sólo con sus discípulos. En efecto, Sócrates es el nombre de una interpretación infinita. Como no hay nada para interpretar, el intérprete tiene que decir todo. Y como hay infinitos intérpretes, la necesidad de defender la propia interpretación y de diferenciar la propia interpretación de las infinitas interpretaciones existentes se proyecta también hacia el infinito. El sentido principal en el que este trabajo se inscribe es pensar, a través de la figura de Sócrates, una política interesante para enseñar y aprender filosofía o, de un modo más amplio, para una educación filosófica ${ }^{4}$.

Sintetizaremos un espacio político paradójico de relación entre quien enseña y quien aprende filosofía a partir de seis antinomias, inspiradas en los esquemas de Derrida y Wolff y las lecturas de Kierkegaard, Nietzsche, Foucault y J. Rancière ${ }^{5}$. El número de seis es arbitrario y los énfasis destacados también lo son. En todo caso, se trata de ayudar a configurar un campo filosófico, por lo tanto, abierto, controversial, inagotable. Las seis exigencias son:

a. La autonomía necesaria e imposible

La enseñanza de la filosofía -o de manera más amplia, una educación filosófica- exige autonomía por todas partes: autonomía de la propia filosofía frente a otros saberes y poderes; autonomía del profesor frente a los marcos institucionales que lo regulan; autonomía de quien aprende frente a quien enseña y los otros aprendices. Las exigencias de autonomía son diversas.

En relación con el exterior de la filosofía, esta antinomia es especialmente importante en este momento educacional. En distintos registros y niveles se inscriben discursos de "educación para la ciudadanía", "formación para la democracia". La enseñanza de la filosofía usualmente acompaña estos discursos como una buena estrategia para alcanzar esos fines. En los países de América Latina en particular se ha vuelto un lugar común que la formación filosófica se justifica en función de su contribución para la educación ciudadana. En la propia comunidad filosófica parece normal aceptar que la enseñanza de la filosofía persiga fines no filosóficos.

¿En qué medida Sócrates puede contribuir para pensar esta situación? La Apología de Sócrates de Platón es un testimonio terminante: allí, la filosofía tiene su propia legalidad y su enfrentamiento con el estado de cosas es radical. Entre la filosofía y la política instituida sólo hay oposición y Sócrates rechaza toda intromisión que pretenda dictar alguna ley para el pensamiento filosófico. Practicar la verdadera política significaría, entonces, no participar

4 Este texto forma parte de una tesis de habilitación para la investigación (HDR) presentada en la Universidad de Paris 8 en septiembre de 2007. Esta tesis consta de cuatro capítulos destinados a examinar lecturas contemporáneas de Sócrates (Kierkegaard, Foucault, Nietzsche e J.Rancière) y una conclusión de la cual este texto forma parte con algunas modificaciones.

5 Como expresado en la nota anterior, las lecturas de estos filósofos se encuentran en ese texto todavía inédito de mi autoría Sócrates: la paradoja de enseñar. 
de la política instituida. Sócrates contrapone, como argumenta Rancière (1996, p. 7), dos políticas: a la política de los políticos opone la política de la filosofía. Entre ambas no hay diálogo, intersección. De modo que Sócrates es un nombre para rechazar cualquier racionalidad política no filosófica que se pretenda imponer a la enseñanza de la filosofía. En contrapartida, Sócrates tampoco renuncia a dictar la ley de la política: justamente ésa es su misión, el sentido de su actividad filosófica. Rechaza la política de los políticos y pretende imponerles una política de la filosofía. De modo que su nombre es también una inspiración para pensar y afirmar, al enseñar filosofía, una otra política que la instituida.

En segundo lugar, la tensión se da al institucionalizar la filosofía. Sócrates también ha sido radical en este sentido y está muy próximo de posiciones como las de Nietzsche y de Rancière. J. Jacotot lo dice con toda claridad: "no hay institución emancipadora" (Rancière, 2003, p. 132); Nietzsche, en Schopenhauer como educador y en Sobre el futuro de nuestros establecimientos de enseñanza, desarrolló una crítica implacable a los profesores de filosofía que se convierten en funcionarios del Estado. En este sentido Sócrates inaugura una tradición, que los cínicos fueron tal vez quienes llevaron más consecuentemente hasta el final, de resistencia a la institucionalización de la filosofía. De modo que Sócrates es también un nombre para poner siempre en cuestión la compatibilidad entre filosofía e institución. Bajo su figura la propia posibilidad de enseñar filosofía en una escuela estará siempre sometida a examen.

En tercer lugar, la tensión no sólo se da entre la filosofía y el mundo exterior sino en el propio interior de la filosofía, entre el pensamiento presente y el pensamiento de los filósofos del pasado, entre el profesor de filosofía y los pensamientos filosóficos del presente, en el debate de las diversas filosofías que pretenden hegemonizar su concepción de filosofía. Sócrates es en este sentido un nombre para hacer de la propia ignorancia el punto de apoyo más importante en la búsqueda filosófica.

En todo caso, la tensión se manifiesta vivamente en la relación entre quien enseña y quien aprende: ¿puede la filosofía en situación educativa no sólo rechazar las finalidades del exterior sino prescindir en su propio discurso de determinar la ley de lo que puede y no puede ser pensado? En algunos diálogos de Platón (Apología, Menón, Eutifrón, Alcibiades, Laques, Lisis y Cármides), Sócrates ocupa la posición de juez del pensamiento. Cambia la forma de su intervención y la reacción de los interlocutores. Los otros se dejan seducir o lo resisten; lo consagran o simplemente lo aceptan. Otros interlocutores más enérgicos, como Trasímaco (cf. Rep. I 335c; 337a), Calicles (Gorg. 489d) y Protágoras (Prot. $167 \mathrm{~d}-\mathrm{e}$ ), se indignan y piden a Sócrates que no pregunte de mala fe. En todo caso, es siempre Sócrates que pretende sancionar lo que es posible o no pensar, quien determina las finalidades legítimas e ilegítimas para el pensamiento de sus interlocutores. Cuando se conversa con Sócrates no hay espacio para pensar fuera de las leyes que dicta para el pensamiento.

Otros lectores de Sócrates divergen en este punto. Kierkegaard (2000) diría que de hecho no hay sino vacío en la filosofía de Sócrates, ninguna ley o finalidad a proponer, ninguna dirección en particular al pensamiento, a no ser la negatividad absoluta de la ironía; el Foucault de los últimos cursos (1984) parece poco preocupado por el modo en 
que Sócrates ejerce el poder del pensamiento frente a sus interlocutores y rescata las finalidades estéticas, relacionadas a una existencia que se cuida y cuida que las otras existencias cuiden de sí mismas. Nietzsche, al contrario, denuncia (1991) la moralización y racionalización de la vida operada por la filosofía de Sócrates; Rancière (1987) condena una actuación movida por la pasión desigualitaria del embrutecedor que somete la inteligencia de los que dialogan con él a su propia inteligencia.

Al fin, con Sócrates la paradoja se potencia. Las lecturas contrastantes surgen de un poder del pensamiento ejercido en direcciones contrarias. Cuando Sócrates anticipa el campo de lo pensable para sus interlocutores, muestra los peligros políticos de una enseñanza filosófica. Cuando lo hace, deja ver su potencia transformadora, la aurora de una nueva política para el pensamiento. ¿Puede un profesor de filosofía enseñar filosofía sin anticipar el campo de lo pensable para el alumno? Si puede, ¿qué diferencia surge en términos del espacio de pensamiento abierto para quién aprende filosofía? ¿Cómo será cubierta esa ausencia? ¿Por qué esa ausencia sería deseable, interesante o necesaria? ¿Cómo saber que aún se está dentro de la filosofía?

b. la transmisión de lo intransmisible

Habitamos una tradición pedagógica fundada en la lógica de la transmisión. Con todo, no resulta claro qué es lo que se transmite en la enseñanza de filosofía. Es notorio que la filosofía no se puede reducir a la transmisión de contenidos filosóficos. Con todo, es también problemática la ausencia de cualquier forma de transmisión. En este punto, Nietzsche y Rancière se unen a Sócrates. En filosofía, nada hay para transmitir a no ser un gesto - que cada uno de esos autores verá de forma diferente- que, en sí mismo, no puede ser transmitido. Sócrates hace sus preguntas, Zaratustra ofrece sus parábolas, Jacotot pone en acto el axioma igualitario y... ya. En esos gestos empieza y termina la puesta en escena pedagógica de la filosofía o, mejor, de una educación filosófica. Ciertamente, Jacotot cuestionaría la pasión desigualitaria que anima el gesto socrático, Nietzsche su moralización y racionalización de la vida, pero ambos aceptarían que es un gesto, una relación con el conocimiento y no un cuerpo de conocimientos -aunque sea en sentido contrario- el que inaugura la práctica de un profesor. Es también cierto que Jacotot no es estrictamente un profesor de filosofía pero permítasenos pensar más ampliamente en una educación filosófica.

De modo que no hay, para Sócrates, Nietzsche y Rancière-Jacotot, nada a transmitir. Claro, hay mucho que transmitir. Pero todo lo que se transmite está sujeto a un gesto primero que es, en sí mismo, intransmisible. Como sugiere Derrida, la experiencia de la filosofía no se transmite, no se enseña. Quien enseña afirma un gesto. Puede ser que quien aprende lo perciba, acepte la invitación y, eventualmente, lo recree. Así, enseñar y aprender filosofía son una cuestión de sensibilidad para compartir un espacio en el pensamiento, para dar lugar en el pensamiento a un movimiento que interrumpe lo que se pensaba para empezar a pensarlo nuevamente, de nuevo, desde otro inicio, a partir de un lugar distinto. El profesor propone ese lugar. Seduce al alumno para acompañarlo, inaugura una nueva relación. La filosofía, el pensamiento, es también una actividad pathética, filial, erótica. 
Sócrates seduce a sus jóvenes interlocutores a entrar al mundo del pensamiento tal y como él lo habita. Sócrates, Nietzsche y Rancière también creen que esa relación sólo puede ser realizada entre dos, de individuo a individuo. Kierkegaard y Foucault probablemente estarían de acuerdo. El alumno decide si ese es su lugar para aprender, y para pensar.

De modo que Sócrates permite pensar una relación pedagógica desde otra lógica que la de la transmisión. El profesor propone un espacio en el pensamiento; se dispone a explorarlo con otros; abre su pensamiento a un trabajo sobre sí con la ayuda de otros; es cierto que Sócrates no parece él mismo hacer siempre lo que enuncia que hace, pero ayuda a pensar el valor de la transmisión en filosofía. Repetimos, la cuestión no es si transmitir o no transmitir; claro que puede haber mucho que transmitir. La cuestión principal es qué servicio cumple la transmisión. Creemos que Sócrates ofrece al menos dos posibilidades: una que él mismo ejemplifica en el Menón, cuando intenta mostrar que nada enseña: aquella que presupone el lugar de llegada del otro, que sabe lo que el otro debe saber y cómo alcanzarlo, que piensa anticipadamente lo que el otro debe pensar; otra, enunciada en el mismo Menón, en la que quien enseña no tiene puntos fijos, problematiza el pensar del otro porque antes lo hace con su propio pensar; se pone a sí mismo en cuestión en el acto de enseñar. Entre esos extremos se juega una exigencia política para el pensamiento entre quien enseña y quien aprende filosofía.

c. El saber y la ignorancia

Consideremos la especial relación de la filosofía con el conocimiento. La filosofía se constituye como un conocimiento particular frente a otros conocimientos como el artístico, científico, religioso. A la vez, desde Sócrates, la filosofía afirma, con no menos fuerza y como forma específica de saber, una relación entrañable con el contrario del saber, la ignorancia: lo único que ella más sabe es que su saber no vale tanto; que ella, en verdad, ignora lo que los otros saberes dicen saber.

En principio, la ignorancia es un vacío, una falta, un defecto y la sabiduría su contrario. Sócrates da vuelta las cosas y sostiene que ese gesto lo hace un filósofo. Las cosas no son lo que parecen. Y hay que salir a mostrar eso a los otros. Hay que cambiar su relación con la ignorancia. Sócrates es el primer educador que no enseña para que los otros sepan lo que no saben sino para que transformen su relación con el saber. Al menos, eso enuncia, aunque no siempre lo haga y quiera que los otros sepan también muchas cosas que él cree saber y que no saben, en primer lugar, que no saben lo que creen saber y que quien no asume saber, esto es, él mismo, es el más sabio de todos.

La filosofía sabe y valora lo que los otros saberes no saben y a lo que escapan: la propia ignorancia. De esa manera, la filosofía reivindica, rescata y le da un estatuto positivo. Pero no es menos notorio que sólo puede hacerlo desde una posición de saber. La ignorancia precisa del saber; la ignorancia sabe y la sabiduría ignora, pero ¿cómo sabe la filosofía el valor de la ignorancia si ella todo lo ignora?

Sócrates, por lo menos según la anécdota que cuenta (¿o inventa?) Platón, legitima su posición en la instancia de saber superior entre los atenienses, Apolo. La filosofía, desacralizadora de todos los saberes, sacraliza su propio punto de partida; ignorante de 
todo saber, sabe su inicio: la ignorancia humana, el deseo de saber, se funda en la sabiduría divina. Ese parece ser un punto fijo que Sócrates no está dispuesto a poner en discusión. Contra lo que piensa Foucault, Sócrates no confuta el oráculo sino que lo usa para legitimar y dar un valor incuestionable a su propia posición de confutador.

A su manera, Rancière funda con Jacotot ese inicio en el axioma de la igualdad. Se encarga de aclarar que no se trata de una verdad a ser demostrada, sino de una opinión a ser verificada. De modo que el recorrido de ese maestro ignorante está fundado en una opinión sabida, verificable. El maestro ignorante ignora todo menos la igualdad de la que parte y no ignora que no puede ignorar ese punto de partida.

¿En qué sentido interesa afirmar esa potencia, como principio, de la ignorancia? ¿Es posible -conveniente, significativo- pensar una ignorancia radical que ni siquiera se sepa a sí misma? Si lo fuera, ¿qué implicaciones tendría ese principio sobre el campo de lo pensable entre quien enseña y quien aprende filosofía? ¿Puede la filosofía permitirse esa excepción? ¿En nombre de quién, de qué fuerzas? Si no lo fuera, ¿qué otro principio -fuera de la igualdad (Rancière-Jacotot) o la superioridad de sí (Sócrates) - interesa pensar para la enseñanza de la filosofía? ¿Hay algo que no puede ignorar un profesor de filosofía? ¿Qué? Por otro lado, ¿qué necesita ignorar? Además, ¿un axioma no instaura un punto sin pensar en el pensamiento? ¿Puede la filosofía permitirse la certeza de un saber, aunque sea el saber de la ignorancia? ¿Cuál es el estatuto filosófico de esos puntos fijos? ¿En qué medida y con qué sentido el pensar puede dirigirse a ellos?

\section{d. El método y su ausencia}

Por un lado, es necesario seguir cierto camino cuando se enseña filosofía. Así, se habla del élenkos como del método socrático. Toda elección metodológica supone compromisos filosóficos. En efecto, la clase magistral, el Telémaco, la cosa en común, las preguntas, la disposición en círculo de alumnos y profesor, la utilización de recursos no tradicionales como DVD's, tiras de historietas, internet, las formas de evaluación, los diversos recursos metodológicos adoptados implican una cierta concepción de la filosofía y de cómo enseñarla. Sin embargo, no existe "el" método filosófico. En cada caso, hay pluralidad de métodos filosóficos y es imposible fijar la filosofía a cualquier método. Más aún, tal vez no sea exagerado afirmar que, mucho más que por una opción metodológica, la filosofía se caracteriza por una determinada relación con este o aquel método. En otras palabras, no hay métodos filosóficos o no filosóficos stricto sensu, sino relaciones filosóficas o antifilosóficas con los diversos métodos de enseñanza. Por supuesto que hay más oportunidades de que la filosofía aparezca de una lectura problematizadora de un diálogo de Platón que al asistir a un video de un té de canasta de señoras bien, pero no hay método que garantice la filosofía así como no hay método que la impida tajantemente. Leer un clásico puede ser más antifilosófico que leer la Biblia; el círculo puede ser un instrumento de control y disciplina más velado, sutil y eficaz que una clase magistral. Los ejemplos podrían multiplicarse.

Las cuestiones metodológicas suelen ser las más urgentes y angustiosas para el profesor de filosofía. Sin negar su relevancia, importa notar las concepciones de filosofía que esas 
demandas suponen y también los sentidos que suelen otorgarle. En este sentido, Sócrates ayuda a pensar: no es una manera fija de relacionarse con sus interlocutores sino el sentido para el que lo hace lo que parece estar siempre presente en sus conversaciones. Nicias lo dice claramente en el Laques: al conversar con Sócrates sus interlocutores fatalmente se verán enfrentados a pensar y ocuparse de sí mismos. Puede cambiar el lugar, puede adecuarse la estrategia, pueden trasformarse las preguntas, pero lo que interesa es que el camino dispuesto permita a cada quien encontrarse consigo mismo en el pensamiento y poner en cuestión el espacio que allí se habita.

Los lectores de Sócrates lo reconocen como fundador de un método: Kierkegaard, del irónico; Foucault, del filosófico; Nietzsche, del dialéctico; Rancière, del embrutecedor. Creemos que Sócrates muestra algo más, que en su enseñanza, la filosofía radica más en una posición abierta con un método que en la fijación de este o aquel método; que cuando ella se fija en un método (como en el Eutifrón o el Menón) pierde capacidad de desplegar sus sentidos; que el método es el de quien aprende, el que permite recorrer con potencia y autonomía, los caminos del pensamiento.

\section{e. Dentro y fuera de los muros}

En las últimas dos décadas se han multiplicado iniciativas para sacar a la filosofía de sus muros: café filosófico, filosofía con niños, consulta filosófica, universidades populares de filosofía, filosofía en las prisiones... estos son algunos de esos nuevos nombres e interlocutores.

Desde la academia filosófica, es frecuente cuestionar, impugnar o simplemente ignorar estas iniciativas con el argumento de que atentan contra la unidad, pureza o especificidad de la disciplina. Por su parte, quienes propician estos movimientos relativizan el valor de esa unidad y, al contrario, valorizan la apertura del discurso filosófico.

¿Puede esa apertura de la filosofía ser realizada manteniendo una cierta especificidad que permita que sea aún llamada filosofía? Sócrates muestra no sólo que esa apertura es posible sino necesaria; que ambas condiciones son consustanciales a la propia práctica de la filosofía: por un lado, Sócrates no rechaza ningún interlocutor, ningún espacio, ninguna invitación; la filosofía está en él apegada a la vida; por el otro, es siempre una y la misma actividad: examinar, preguntar, confutar.... Lo que Sócrates parece sugerir en este punto es que el filosofar y la filosofía van juntos... o son dos aspectos de una y la misma actividad.

Sócrates muestra también que lo propio de la filosofía no tiene que ver con fijar el pensamiento. Fue tan lejos en este punto que resistió hasta la propia escritura del pensamiento. Algunos discípulos le han hecho caso, otros no. Platón fue el más "desobediente": los diálogos, la academia, las aventures políticas en Sicilia. En todo caso, Sócrates escapa a todas esas pretensiones: los diálogos no son sus conversaciones; su lugar son lugares: en el ágora, en el gimnasio, en la calle; su vida es exageradamente humana para ser tan heroica (o demasiado filosófica para ser tan concreta como lo ha querido Jenofonte; o severa en exceso por ser tan cómica como ha querido Aristófanes).

Nadie ha estado tan cerca filosóficamente de Sócrates como Platón. ¿Cómo negarlo? Pero también, ¿cómo no notar que nadie ha estado filosóficamente más lejos por la misma fuerza filosófica de esa pretensión y la traición imperdonable que esa fuerza no 
podía dejar de cometer? La tensión supera los nombres propios. En todo caso, Sócrates ilustra un gesto extremo, hoy casi imposible de repetir, una exigencia del pensamiento por mantener cierta unidad y a la vez por recrearse en su contacto con las diversas formas de la vida.

\section{f. Transformar y descolonizar}

En América Latina, si desde la derecha, la enseñanza de la filosofía ha estado dirigida a la legitimación y conservación del estado de cosas; desde los sectores autoproclamados de izquierda, se la ha pensado para la transformación de un orden social por demás injusto y excluyente, la filosofía escolarizada formaría los seres críticos que se volverían contra el orden que administra el propio sistema escolar para subvertirlo, transformarlo. La lectura de Sócrates ayuda a resituar y reconfigurar la relación entre filosofía y transformación.

Sócrates sugiere que la filosofía tiene un compromiso con la transformación del propio pensamiento. Es cierto que a veces fracasa (como en el Eutifrón), no sólo porque el otro continúa pensando de la misma manera, sino porque él mismo continúa situado en el mismo lugar en el pensamiento. Pero cuando funciona a pleno, abre un espacio de transformación para unos y otros, en relación con su pensamiento.

De esa manera, enseñar y aprender filosofía es una oportunidad para transformar lo que pensamos y con ello el modo como vivimos y somos. Con Sócrates sucede lo que Derrida apunta en otra intervención, esta vez en un coloquio africano en diciembre de 1978 acerca de la relación de África con la filosofía occidental (1990, p. 155-179). Allí Derrida sugiere que no es interesante sólo repetir y reproducir la historia de la filosofía occidental pero, por otro lado, no parece más interesante simplemente ignorar, oponerse o dar vuelta esa tradición. Al contrario, el desafío principal es una obra infinita de descolonización del propio pensamiento para no recrear la lógica colonizadora que habita aquel pensamiento y la realidad en la cual se inscribe. Derrida afirma que no existe la descolonización, sino movimientos parciales, heterogéneos, diferentes de un lugar a otro.

El desafío lanzado por Derrida se actualiza paradigmáticamente con Sócrates, iniciador y modelo de profesores de filosofía. No parece interesante negar la tradición que Sócrates inaugura; pero tampoco simplemente ignorarla o darla vuelta. Creemos haber señalado que Sócrates es muchos Sócrates y que hay muchas fuerzas allí presentes a favor y en contra de la trasformación de sí en el pensamiento. Es innegable que Sócrates afirma relaciones de poder desiguales, jerárquicas; pero no es menos cierto que abre la posibilidad de pensar lo que, sin ese contacto, muy probablemente no sería posible pensar. Sócrates es un enigma por las fuerzas contradictorias que su figura parece portar sin demasiada incomodidad.

Dada la enorme influencia de Sócrates, no sólo en la historia de la filosofía sino en la historia de las ideas pedagógicas, nos plantea un enorme desafío. En la forma de una pregunta, ¿qué querrá decir descolonizar nuestra relación con Sócrates como ejemplo, modelo, paradigma de profesor de filosofía? En este trabajo hemos intentado dar algunas notas en esa dirección. Se trata de usar a Sócrates como un símbolo para pensar, más 
ampliamente, lo que significa actualmente enseñar filosofía de una forma descolonizadora. O dicho en otras palabras, ¿puede la enseñanza de la filosofía contribuir a descolonizar el pensamiento? ¿De qué manera?

Como afirma Derrida, podríamos continuar proyectando exigencias infinitamente, dándoles otra forma, otro número, otro nombre. No nos seduce la idea de fijar nada en el campo de la filosofía. El argelino afirma: "la unidad de la lengua es siempre un simulacro revestido y manipulado" (ibid, p. 163) y comenta que es necesario valerse de la multiplicidad que habita cada corpus lingüístico para luchar contra la colonización en general y contra la colonización de ese monolingüismo y monologismo en particular. Allí radica tal vez, uno de los desafíos más difíciles con Sócrates, no dejarse seducir por una única lengua.

La filosofía puede ser el trabajo más liberador, pero también el más dominador del pensamiento. Basta escuchar a algunos de los infinitos Sócrates que habitan ese nombre: el Sócrates ironista, el que cuida, el que se opone a la vida, el que vive de la pasión desigualitaria. El desafío se da en cada pensamiento, en cada lectura, en cada escritura, en cada ingreso a un aula: ¿al servicio de qué fuerzas proponemos el juego de la filosofía? La tarea de descolonizar el propio pensamiento es infinita. Se postula no sólo para enseñar filosofía, sino también para una enseñanza filosófica.

Se vuelve, siempre, sobre el propio pensamiento. Así sucede también al leer a Sócrates: antes de interpretar lo que verdaderamente dijo, es un desafío mayor enfrentarse con su enigma como una oportunidad para iniciar ese trabajo descolonizador del propio pensamiento, que nunca termina. Quizá, este trabajo descolonizador del pensamiento inspire otros movimientos descolonizadores. Así, filosofía y educación se habrán encontrado, sin descifrar el enigma, sino pensándolo. Pensar y practicar una educación filosófica descolonizadora, -enigmática y paradójica-, sensible a las tensiones que habitan la relación entre quien ocupa el lugar de enseñar y quien habita el espacio de aprender es no sólo un indispensable programa de investigación filosófica sino, más aún, una de las tareas más infinitas de un profesor de filosofía, si es que existen los "más" y los "menos" habitando ese espacio infinito.

\section{Referencias bibliográficas}

Brickhouse, Thomas C., Smith, Nicholas D. Socrates on Trial. Princeton: Princeton University Press, 1989.

Burnet, John. Plato's Euthyphro, Apology of Socrates and Crito. 2. Ed. Oxford: Oxford University Press, 1954.

Clay, Diskin. "The Origins of the Socratic Dialogue." In: WAERDT, Paul A Wander (ed.). The Socratic Movement. Ithaca, NY: Cornell, 1994, p. 23-47.

Dávila, Jorge. "Ética de la palabra y juego de la verdad." In: Gros, Frédéric; Lévy, Carlos (orgs.). Foucault y la filosofía antigua. Buenos Aires: Nueva visión, 2004, p. 143174.

Derrida, Jacques. Le droit a la philosophie. Paris: Galilée, 1990. . La carte postale. De Socrate à Freud et au-delà. Paris : Flammarion, 1980. 